\title{
A TV CULTURA E SEU PAPEL NO PROCESSO DE IMPLANTAÇÃO DA MULTIPROGRAMA- ÇÃO NO BRASIL
}

\author{
VIVIANNE LINDSAY CARDOSO \\ UNIVERSIDADE ESTADUAL PAULISTA \\ SÃO PAULO, SÃO PAULO, BRASIL \\ E-MAIL: VIVIANNELC@HOTMAIL.COM \\ JULIANO MAURÍCIO DE CARVALHO \\ UNIVERSIDADE ESTADUAL PAULISTA \\ SÃO PAULO, SÃO PAULO, BRASIL \\ E-MAIL: JULIANO@FAAC.UNESP.BR
}

HTTP://DX.DOI.ORG/10.5902/2316882X22464 


\section{A TV CULTURA E SEU PAPEL NO PROCESSO DE IMPLANTAÇÃO DA MULTIPROGRAMAÇÃO NO BRASIL}

Resumo: Nos últimos anos, entre as contribuições mais significativas da TV Cultura está a implantação da multiprogramação, por meio dos canais Univesp TV e Multicultura. Em um panorama histórico da implantação, por meio de pesquisa bibliográfica e documental, com referencial teórico da Economia Política da Comunicação e Cultura, identifica-se a iniciativa como relevante para a implantação da televisão digital e a comunicação pública no Brasil.

Palavras-chave: Multiprogramação; Televisão Pública; Televisão Digital; Políticas Públicas de Comunicação.

\section{TV CULTURA Y SU PAPEL EN LA MULTIPROGRAMACIÓN PROCESO DE IMPLANTACIÓN EN BRASIL}

Resumen: En los últimos años, entre las contribuciones más significativas de la TV Cultura es la implementación de multiprogramación, a través de los canales de televisión y Univesp Multicultura. En una visión histórica de la ejecución, a través de la investigación bibliográfica y documental, con el marco teórico de la Economía Política de la Comunicación y la Cultura, identifica la iniciativa sea pertinente para la aplicación de la comunicación digital y la televisión pública en Brasil.

Palabras clave: Multiprogramación/Multicanalización; Televisión pública; Televisión digital; Políticas públicas de comunicaciones.

TV CULTURA AND ITS ROLE IN MULTIPROGRAMMING IMPLEMENTATION PROCESS IN BRAZIL

Abstract: In recent years, among the most significant contributions of TV Cultura is the implementation of multiprogramming, through UNIVESP TV and Multicultura channels. In a historical overview of the implementation, through bibliographical and documentary research, with theoretical framework of the Political Economy of Communication and Culture, the paper identifies the initiative as relevant for the implementation of digital communication and public television in Brazil.

Keywords: Multiprogramming; Public Television; Digital TV; Public Communications Policy. 


\section{INTRODUÇÃO}

A TV Cultura é uma emissora pública e educativa de significativa relevância histórica para o desenvolvimento da comunicação pública não apenas para o estado de São Paulo, onde se encontra a sede da emissora, mas também para o país. Desde sua fundação, na década de 1960, tem como característica uma trajetória de superações e inovações, buscando oferecer um conteúdo voltado, especialmente, à educação e à cultura. E a emissora assim atua mesmo com diversas limitações e dificuldades financeiras e divergências políticas, especialmente identificadas, vivenciadas e debatidas nos últimos anos - que não serão tratadas neste texto, pois o objetivo aqui é demonstrar que a TV Cultura viabilizou relevante contribuição às reflexões referentes aos estudos sobre a implantação da televisão digital no Brasil. Tal contribuição caracteriza-se quando pensada especialmente para a aplicabilidade do uso da tecnologia para a comunicação pública, com a implantação de dois canais de multiprogramação, o Univesp TV e o Multicultura.

Desde o ano 2000, com o processo de implantação da tecnologia da televisão digital, o Brasil tem vivenciado um dos momentos mais significativos no desenvolvimento da televisão, especialmente no campo da comunicação pública. Desde sua criação, a mudança marca discussões quanto às suas potencialidades, finalidades e acessibilidade, seja nos âmbitos político, econômico, tecnológico, comercial ou social. Políticos, profissionais, estudiosos e o próprio telespectador acompanham e se tornam personagens desta história ainda em construção. Alta definição de imagem e som, interatividade, multiprogramação, mobilidade, portabilidade e convergência são as principais novidades apresentadas que atraem e instigam estudos e pesquisas.

A multiprogramação é um ponto polêmico, controverso e, fundamentalmente, restrito. Seja ela restrita, ilegal, ameaçadora, democrática, inovadora ou repetidora, a multiprogramação vem construindo sua história no Brasil permeada por divergências, inquietações e possibilidades. Entre as contribuições e inovações mais significativas para a televisão brasileira e a própria televisão pública realizadas pela TV Cultura nos últimos anos está a implantação da multiprogramação por meio dos canais Univesp TV e MultiCultura, inaugurados em 26 de agosto de 2009. Os canais seguem, em teoria, os princípios dos artigos 222 e 224, na busca por univer-

Rev. Cad.Comun, Santa Maria, v.20,n.1, art 1, p.1 de 24, jan/abr.2016 
salizar o direito à informação e à comunicação, em um trabalho contínuo de inovação e experimentação (FPA, 2010), autorizados a funcionar em caráter científico e experimental. Implantados em um processo de enfrentamento junto ao Ministério das Comunicações, caracterizam-se como os primeiros canais de multiprogramação do Brasil a entrar no ar e, ainda, não pertencerem ao Governo Federal.

\section{A TV CULTURA E A CHEGADA DA TECNOLOGIA DIGITAL}

Em 20 de setembro de 1960 foi inaugurada a TV Cultura, Canal 2, quinta emissora de televisão da cidade de São Paulo. Na década de 1960, a TV Cultura foi adquira pelo Governo do Estado de São Paulo. Por meio de um projeto ousado do governador Abreu Sodré, o estado de São Paulo passou a possuir um canal próprio educativo para a veiculação de uma programação diversificada. Para isso o governo criou a Fundação Padre Anchieta (FPA), em setembro de 1967, por meio da Lei nº 9.849/1967, uma entidade de direito privado para gerir as futuras rádio e emissora, que passou a ser de caráter educativo a partir do Decreto-Lei $n^{\circ} 236$, de 28 de fevereiro de 1967, que complementa e modifica a Lei ${ }^{\circ}$ 4.117, de 27 de agosto de 1962. Após um período de pausa no processo de transição, as atividades voltaram ao ar em 15 de junho de 1969, quando se deu o início da segunda fase de emissora.

Desde então, a TV Cultura se caracterizou no Brasil como uma das principais referências como canal público e educativo, sendo responsável por produções inovadoras, premiadas internacionalmente e de ampla aceitação da audiência, especialmente no viés de produções voltadas ao público infantil, entre eles Rá-Tim-Bum, Castelo Rá-Tim-Bum, Glub Glub, X-Tudo, entre outros. Utilizando a fundamentação teórica da Economia Política da Comunicação e tendo como metodologia o levantamento bibliográfico e documental, delimita-se aqui o panorama histórico da multiprogramação no Brasil a partir da regulamentação da televisão digital e a implantação dos primeiros canais de multiprogramação por iniciativa da TV Cultura, em 2009.

O período de gestão do jornalista Paulo Markun, responsável pela implantação da multiprogramação na TV Cultura, entre 2007 e 2010, caracterizou-se como um dos mais significativos para o desenvolvimento da tecnologia digital na emissora. Funcionário por dez anos da TV Cultura,

Rev. Cad.Comun, Santa Maria, v.20,n.1, art 1, p.1 de 24, jan/abr.2016 
eleito pelo Conselho Curador em 14 de junho de 2007, estruturou sua gestão baseada na premissa de que a missão seria "contribuir para a formação crítica do homem para o exercício da cidadania, produzindo conteúdo educativo, cultural e de interesse público para os paulistas e brasileiros." (RELATÓRIO DE GESTÃO, 2010, p. 5).

A TV Cultura foi a primeira emissora de televisão aberta a operar um canal exclusivo de exibição pela internet, o IPTV Cultura (www.iptvcultura.com.br), além de manter portal da TV Cultura, o portal da Fundação Padre Anchieta e o site de compra dos produtos com a marca da fundação. A fundação ainda atuou por meio da Cultura Data, unidade de pesquisa e da Unidade Cultura Educacional, destinada à geração de serviços que abrangiam a produção de televisão para a formação de professores e monitores de animação cultural e/ou apoio a movimentos sociais e edição de material paradidático para alunos da rede pública.

A transição da TV Cultura para a tecnologia digital vinha sendo trabalhada anteriormente à gestão de Markun, desde o ano 2000, com a digitalização da produção da emissora, além da aquisição de equipamentos como câmeras, novo sistema de programação para exibição de chamadas promocionais e publicidade, estações digitais de edição não linear e ampliação da rede de computadores (LIMA, 2008). Ao longo dos anos, toda estrutura foi sendo gradativamente digitalizada. O início da digitalização de seu acervo foi em 2005. Em dezembro de 2007, a TV Cultura deu início às suas transmissões digitais na cidade de São Paulo.

A criação da televisão digital destaca-se positivamente em sua regulação pela constante preocupação com a questão da educação, acessibilidade e desenvolvimento social, iniciada a partir da instituição do Sistema Brasileiro de Televisão Digital (SBTVD) pelo Decreto $n^{\circ} 4.901$, de 26 de novembro de 2003. Entre seus objetivos, estão descritos a finalidade de promover a inclusão social, a diversidade cultural do país e a língua pátria por meio de acesso à tecnologia, visando à democratização da informação, propiciar a criação de rede universal de educação a distância e contribuir para a convergência tecnológica e empresarial dos serviços de comunicação.

A partir da implantação desta tecnologia, um dos pontos mais debatidos nos últimos anos é dispositivo de comunicação que foi implantado e disponibilizado para o país: a multiprogramação. Ela é definida como "a transmissão simultânea de vários programas dentro de um mesmo canal

Rev. Cad.Comun, Santa Maria, v.20,n.1, art 1, p.1 de 24, jan/abr.2016 
de $6 \mathrm{MHz}$ ", conforme NORMA n 01/2009. A multiprogramação, ou "ocupação compartilhada de um canal $(6 \mathrm{MHz})$ por diversas emissoras, sendo que cada emissora possui um espaço próprio, autônomo, dentro desse canal, como se fossem sub-canais", conforme consta no Relatório do Grupo Temáticos de Trabalho "Migração Digital”, do I Fórum Nacional de TVs Públicas (2007), pode ser um "modelo estratégico para as televisões públicas por permitir maior representação da diversidade e por ser o meio de atender as necessidades de produção e veiculação de conteúdos que atendam todas as demandas da sociedade" com os seguintes benefícios: ampliação do número de canais - mais conteúdo, possibilidade de alternar alta definição (banda) e multiprogramação (divisão de banda em até quatro programações standard) - e conteúdo diferenciado.

Regulamentada pela Norma Geral para Execução dos Serviços de Televisão Pública Digital n 01/2009, a multiprogramação é autorizada a ser utilizada exclusivamente pela União Federal, com o objetivo de transmitir assuntos ligados ao Poder Executivo, educação, cultura e programação voltada a interesses regionais, podendo ser utilizada somente nos canais a que se refere o Artigo 12 do Decreto $n^{\circ} 5.820 / 2006$, consignados a órgãos e entidade integrantes dos poderes da União, por quatro canais digitais de radiofrequência com largura de banda de seis megahertz (6 MHz). Regulamentam ainda a multiprogramação no Brasil

Neste cenário, a TV Cultura foi a única emissora a ter a autorização especial para a implantação da multiprogramação. Mesmo sendo uma emissora pública e educativa, foi preciso ampla negociação entre o Ministério das Comunicações, por meio do então ministro Hélio Costa, e o ex-presidente da Fundação Padre Anchieta, Paulo Markun, responsável por romper a própria legislação vigente por acreditar na potencialidade e inovação da multiprogramação e colocar no ar os dois canais da TV Cultura, o MultiCultura e o Univesp TV. O resultado da disputa foi o Despacho do ministro Hélio Costa, em 7 de maio de 2009, publicado no Diário Oficial da União (DOU), autorizando a transmissão dos canais em caráter científico e experimental' .

Em 2012 o Governo Federal publicou a Portaria nº 106/2012 que es-

1 Mais detalhes deste processo de negociação para a implantação da multiprogramação pela TV Cultura podem ser encontrados no artigo dos próprios autores: Face Paulista da TV Digital: Reflexões sobre a multiprogramação na TV Cultura. Disponível em: http://www.seer.ufs.br/index.php/eptic/article/view/111. Acesso em: 24/02/2013.

Rev. Cad.Comun, Santa Maria, v.20,n.1, art 1, p.1 de 24, jan/abr.2016 
tabelece normas para a utilização de multiprogramação com base no disposto dos artigos 12 e 13 do Decreto $n^{\circ} 5.820 / 2006$, no qual determina, novamente, apenas aos órgãos dos Poderes da União consignatários de canais digitais de $6 \mathrm{MHz}$ o direito de utilizar o recurso de multiprogramação para transmitir programações simultâneas em no máximo quatro faixas. Tais canais de multiprogramação podem celebrar convênios ou instrumentos similares para o compartilhamento da programação de forma não onerosa, desde que receba todo o conteúdo da geradora, com órgãos da União, autarquias e fundações públicas dos estados, do Distrito Federal e dos municípios, com a finalidade de atender aos seguintes requisitos e objetivos: finalidades educativa, artística e cultural; divulgação de produções culturais e programas locais ou regionais; estímulo à produção independente; divulgação de atos, sessões, projetos e eventos institucionais dos poderes públicos federal, estadual e municipal; ou aplicações de serviços públicos de governo eletrônico no âmbito federal, estadual e municipal. Como complemento à portaria, foi publicada no final de 2012 a Portaria $n^{\circ} 471$ que altera o artigo $3^{\circ}$ da Portaria $n^{\circ} 106 / 2012$, determinando que a consignatária veicule programação própria em pelo menos uma faixa de programação e não duas, como inicialmente determinado.

Mesmo restritiva, a Portaria $\mathrm{n}^{\circ}$ 106/2012 determina em seu artigo $7^{\circ}$ uma alteração no item 2 da Norma $n^{\circ}$ 01/2007, aprovada pela Portaria MC $n^{\circ} 465 / 2007$, portaria esta que estabelece os procedimentos operacionais necessários para a execução de serviços especiais para fins científicos ou experimentais tendo como objetivo realizar experimentos de transmissão de sinais de radiodifusão ou demonstrações de sistemas desenvolvidos para essa finalidade. A alteração da Portaria n 106/2012 determina que o item 2 passe a vigorar com a seguinte redação: "Para os efeitos desta Norma, são competentes para executar Serviço Especial para Fins Científicos ou Experimentais, além da União, de forma direta, as seguintes entidades: ............"(NR)". Tal alteração cria uma brecha de possibilidade para a implantação multiprogramação nos termos descritos, no entanto, limita a possibilidade ao poder de autorização ao Governo Federal.

Ao ser a única emissora pública do país a receber autorização do Ministério das Comunicações para implantar a tecnologia de multiprogramação em caráter científico e experimental, concedida em 2009, a conquista da TV Cultura gerou uma necessidade de ponderação para o uso da tecnologia nas normatizações posteriores, o que reforça sua contribuição

Rev. Cad.Comun, Santa Maria, v.20,n.1, art 1, p.1 de 24, jan/abr.2016 
para os debates sobre o tema, que permanecem ativos. Em 2016, as emissoras estaduais vêm reivindicando junto ao Ministério das Comunicações o direito de também praticarem a multiprogramação.

Em paralelo, vale lembrar que a televisão pública e educativa, desde sua implantação, por meio do Decreto-Lei $n^{\circ} 236$, de 28 de fevereiro de 1967, tem como dever destinar a divulgação de programas educacionais, mediante a transmissão de aulas, conferências, palestras e debates. As emissoras de rádio e televisão, por sua vez, devem ter como princípio, conforme determina o Artigo 222 da Constituição Federal, finalidades educativas, culturais e informativas. Até o momento, a TV Cultura segue - em teoria - com sua missão definida pela Fundação Padre Anchieta, responsável por gerir a emissora, como uma televisão pública com missão de trabalhar com finalidades educativas, artísticas, culturais e informativas, conforme determina os Artigos 222 e 224 da Constituição Federal, buscando universalizar o direito à informação e à comunicação. (FPA, 2010).

\section{A MULTIPROGRAMAÇÃO}

Entre as potencialidades da tecnologia da televisão digital no Brasil, a multiprogramação, definida por Ferraz (2009), é um dos principais atrativos da tecnologia e caracteriza-se pela possibilidade de transmissão simultânea de múltiplos conteúdos em um mesmo canal de televisão, graças à capacidade de compactação de dados de áudio, vídeo, dados e software, encapsulados e inseridos em um protocolo de transporte, podendo ser compreendidos pelo receptor que possua o mesmo protocolo, assim como acontece com a internet.

A tecnologia permite o uso mais eficiente do espectro de transmissão e o aumento do número de programas oferecendo mais conteúdo, maior concorrência e diferentes usos — serviço, governo, bancos etc. alta qualidade de imagem e som e interatividade, criando expectativa por parte da cadeia produtiva e do telespectador gerando maiores receitas, maior interação com o público, maior divertimento e mais fontes de informação. A emissora pode ter a liberdade de decidir transmitir diversos programas ao mesmo tempo, ou transmitir o conteúdo de diversas câmeras, inclusive com ângulos diversos, permitindo que o usuário assista o programa multicâmera do modo que preferir (FERRAZ, 2009).

Mesmo considerando as diversas combinações possíveis que podem

Rev. Cad.Comun, Santa Maria, v.20,n.1, art 1, p.1 de 24, jan/abr.2016 
ser feitas com a multiprogramação serem interessantes, Ferraz (2009) avalia que nos vários países em que a televisão digital vem sendo implantada, faltam modelos de negócios consistentes para a multiprogramação, e, por isso, tem recebido menos atenção. Mesmo assim, avalia que canais de interatividade com suas aplicações motivam o maior desenvolvimento da engenharia e são cruciais para a consolidação do sucesso dessa funcionalidade. Além disso, a forte expectativa de mudanças na forma de comunicação entre a televisão e o telespectador, muda a concepção deste último, passando a ser chamado de usuário. (FERRAZ, 2009).

O Relatório do Grupo de Trabalho "Migração Digital” do I Fórum Nacional de TVs Públicas, realizado em 2006, destaca que cabe a "televisão pública contribuir para integrar a maioria da população aos benefícios da tecnologia, bem como eliminar diferenças de acesso à capacidade de produção de conteúdos" e avalia a multiprogramação como um "modelo estratégico para as televisões públicas por permitir maior representação da diversidade e por ser o meio de atender as necessidades de produção e veiculação de conteúdos que atendam todas as demandas da sociedade" com os benefícios de ampliar o número de programas para oferecer mais conteúdo e de modo diversificado. O relatório de contribuição do Intervozes ao II Fórum Nacional de TVs Públicas, divulgado em maio de 2009, do ponto de vista econômico, apresenta a multiprogramação preconizada pela televisão digital como um gerador de impactos para a estrutura de mercado da televisão, possibilitando a entrada de novos agentes no espectro.

Pieranti e Winner (2009) consideram, no entanto, que a legislação vigente no Brasil é defasada, apresentando dificuldades para se lidar com ela e viabilizar novas funcionalidades da comunicação de massa, como a multiprogramação e a interatividade, não possuindo um marco legal unificado ou um quadro normativo composto por regras e princípios harmônicos entre si para a regulação de diferentes serviços. A dificuldade, para os autores é a ausência, ao menos, de uma legislação que considere serviços mais recentes e a convergência tecnológica, o que acaba resultado em dificuldades para uma regulação apropriada da comunicação social no presente, como vem acontecendo com a multiprogramação.

A desmassificação provocada pela televisão digital e suas potencialidades gera uma nova realidade reflexiva apresentada por Bolaño e Brittos (2007) como o reconhecimento da existência de uma pluralidade de 
interesses, relativos a consumidores, emissoras e outros setores da indústria brasileira que, para serem atendidos, devem alterar sua lógica social até então adotada. No Brasil a televisão é um meio de comunicação muito mais popularizado por suas características de entretenimento do que de desenvolvimento social. Pode-se dizer que as características da indústria cultural são explícitas, no entanto a televisão pública pode e deve se destacar pelo estímulo à produção de conteúdos digitais alternativo, interativos e inovadores, e para Pieranti e Winner (2009) a multiprogramação torna-se um modelo adequado para bem realizar essa missão.

A TV Cultura representar um elemento importante nesta quebra de entraves e resistências, podendo servir de modelo para outras televisões públicas. As regulações determinadas pelas políticas públicas são fatores determinantes no processo de desenvolvimento da multiprogramação e sua devida utilização. A proposta de implantação da multiprogramação pela TV Cultura remete a um resgate histórico dos objetivos educacionais da emissora e cria um cenário propício à reflexão quanto a relevância social da TV Cultura como televisão pública quando atua cumprindo seus princípios e a contribuição que os dois canais podem dar aos estudos sobre televisão digital no Brasil. É pertinente considerar que a concretização e o aperfeiçoamento do projeto inicial, idealizado em 2010, estão diretamente ligados à necessidade de investimentos públicos e empenho dos profissionais e políticos envolvidos que abarcam políticas públicas efetivas oriundas do estado de São Paulo.

\section{O MULTICULTURA}

O Multicultura, sintonizado no sinal digital, foi idealizado paralelamente ao canal Univesp TV como complemento para a nova proposta de programação oferecida pela Fundação Padre Anchieta. O canal, criado graças à tecnologia digital, foi idealizado buscando oferecer mais cultura, conhecimento e educação, ampliando sua área de atuação e cobertura. Iniciada a implantação em 2010, entrou no ar exibindo programas, séries e especiais contidos no acervo dos 40 anos da TV Cultura que já tenham sido digitalizados. A proposta foi oferecer temas como ciência, dramaturgia, musicais, documentários, entrevistas raras, juvenis e outros.

Inicialmente, buscando uma implantação da multiprogramação de modo mais sólido, não sendo limitada apenas a um canal, considerando a

Rev. Cad.Comun, Santa Maria, v.20,n.1, art 1, p.1 de 24, jan/abr.2016 
dimensão e valor histórico do acervo existente que já vinha sendo digitalizado e sua limitação legal para a comercialização do conteúdo produzido ao longo da história da TV Cultura, deu-se o início da transmissão do Multicultura, apresentando uma programação temática diária, retransmitindo o acervo da emissora que completou 40 anos em 2009. Posteriormente, a programação temática foi substituída por uma programação diversificada, mas mantendo a transmissão de seu acervo. O Canal Multicultura, além do acervo, começou a exibir produção própria com pequenos programas (programetes) alusivos a datas especiais.

Em 2016 o Multicultura se define como um canal destinado a tratar assuntos de cultura, conhecimento e educação, buscando "contribuir com a melhoria da qualidade da Educação Básica e colaborar para a democratização do acesso ao conhecimento, conectando a vida social e cultural às novas descobertas científicas e a fatos e tendências da realidade contemporânea" (MULTICULTURA, 2016). Atualmente a Fundação Padre Anchieta possui acordo com a Fundação Roberto Marinho e Globo para parceiras de conteúdo na programação no canal que passa a ser definido como Multicultura Educação. Mesmo assim, parte de seu conteúdo continua sendo de retransmissão de conteúdos veiculados pela TV Cultura e/ou que pertençam ao seu acervo.

\section{O UNIVESP TV E O PROJETO UNIVESP}

Com programação diária, o canal Univesp TV, com sinal digital, foi criado visando apoiar o Programa Univesp (Universidade Virtual do Estado de São Paulo), iniciativa da Secretaria de Ensino Superior do Estado de São Paulo, por meio do Decreto $n^{\circ} 53.536 / 2008$. A proposta foi utilizar as tecnologias de comunicação e informação para desenvolver o ensino superior público e de qualidade com mediação da internet e da televisão no processo de formação dos alunos. Com sinal digital para a Grande São Paulo e parabólica digital em todo o país, o canal surgiu com o objetivo de ser um instrumento de apoio aos estudantes e oferecer ao espectador um conteúdo efetivamente educativo utilizando entrevistas, reportagens, debates, filmes e documentários como conteúdo de interesse geral.

O Univesp TV buscou em sua proposta inicial desenvolver uma grade de programação com espaço para programas diretamente ligados aos cursos e vinculados às aulas. Trata-se de uma ação cooperativa, articulada

Rev. Cad.Comun, Santa Maria, v.20,n.1, art 1, p.1 de 24, jan/abr.2016 
pela Secretaria de Ensino Superior do Estado de São Paulo com as universidades estaduais paulistas - Universidade de São Paulo (USP), Universidade Estadual Paulista "Júlio de Mesquita Filho" (Unesp) e Universidade Estadual de Campinas (Unicamp) e com o Centro Paula Souza, com apoio da Fundação de Amparo à Pesquisa no Estado de São Paulo (Fapesp), da Fundação do Desenvolvimento Administrativo Paulista (Fundap), da Fundação Padre Anchieta e da Imprensa Oficial do Estado de São Paulo (UNIVESP, 2010).

Os cursos, oferecidos em modalidade semipresencial, foram idealizados para terem encontros semanais obrigatórios e as atividades complementares desenvolvidas por meio de ferramentais digitais e virtuais viabilizadas pela internet, programas da Univesp TV e vídeoaulas. O primeiro curso oferecido foi o de Pedagogia, realizado pela Unesp e com 1.350 vagas, para as quais candidataram-se oito mil pessoas. A programação inicial era diária, composta por quatro módulos de quatro horas inéditas, sendo repetidos ao longo da programação, com veiculação de programas ao vivo nos horários das atividades presenciais. Em 2009, foi contabilizada a produção ou compra de 339 programas diferentes, equivalentes a 196 horas de produção, com a média de transmissão de 15 horas diárias de programação (RELATÓRIO DE GESTÃO, 2010; UNIVESP TV, 2012).

A seleção dos alunos foi planejada para ser organizada pelas universidades e instituições públicas envolvidas de acordo com critérios específicos de cada curso, tanto de graduação quanto especialização ou línguas. Além da graduação em Pedagogia, foram criados os cursos de especialização em Ética, Valores e Cidadania na Escola; Ética, Valores e Saúde na Escola; tecnologia em Processos Gerenciais, além de cursos extracurriculares de inglês e espanhol básicos.

Utilizando as tecnologias da informação e comunicação, os cursos são ministrados com apoio de ferramentas computacionais por meio da plataforma do projeto Aprendizado Eletrônico (Ae). A plataforma eletrônica Tidia-Ae, viabilizada pelo projeto Aprendizado Eletrônico (Ae), foi desenvolvida pelo Programa Tecnologia da Informação no Desenvolvimento da Internet Avançada (Tidia) da Fapesp. Por meio da plataforma eletrônica Tidia-Ae os alunos têm acesso aos conteúdos preparados especificamente para cada curso, utilizando ferramentas de interatividade para a realização das atividades que são preparadas para cada fase do curso e devem ser cumpridas respeitando um calendário que se desenvolve para-

Rev. Cad.Comun, Santa Maria, v.20,n.1, art 1, p.1 de 24, jan/abr.2016 
lelamente aos programas transmitidos na Univesp TV. Todas as atividades concluídas são encaminhadas para um tutor que segue o desenvolvimento do aluno, avaliando-o e dando orientações. Visando aos acessos posteriores do próprio aluno, do tutor ou orientador, os trabalhos realizados são armazenados em um banco de dados. São consideradas presenças as atividades realizadas digitalmente e as aulas presenciais.

Os programas abertos de acesso gratuito são produzidos prioritariamente para atender as demandas dos cursos, mas também são voltados ao interesse geral, atendendo ao princípio e o slogan do canal: para quem quer saber mais e aprender sempre (TEIXEIRA, NAOUM, 2012). Desde o dia 4 de outubro de 2010, o Univesp TV passou a transmitir simultaneamente a programação do canal de multiprogramação também na internet por meio do site www.univesp.tv.br, o que viabilizou o acesso a seu conteúdo em todo território nacional e internacional. O programa Univesp desenvolveu ainda a revista digital temática Pré-Univesp voltada ao apoio aos estudantes pré-universitários. Com periodicidade mensal, a publicação aborda temas da atualidade presentes na matriz curricular para ensino médio e ingresso à universidade (PROGRAMA UNIVESP, 2011).

Em 2016, o canal digital de multiprogramação tem como objetivo principal "apoiar o aprendizado dos alunos de cursos da Univesp, através de programas específicos e também de interesse geral” (UNIVESP, 2016). O canal exibe programas de produção própria e conteúdos produzidos pela BBC, Channel 4, Open University, PBS e Europe Images, entre outras. São trasmitimas também aulas de disciplinas de cursos regulares de graduação e pós-graduação de USP - Universidade de São Paulo, UNESP - Universidade Estadual Paulista "Júlio de Mesquita Fiho" e UNICAMP - Universidade de Campinas, entre outros programas como Complicações, Educação Brasileira, Ensino Superior, Desafios da Educação e Fala, Doutor que discutem temas do momento, especialmente a Educação.

\section{EXPANSÃO DA MULTIPROGRAMAÇÃO}

A implantação da multiprogramação no Brasil é um assunto que vem sendo tratado pela mídia brasileira desde a década de 1990, como uma das características mais atrativas da tecnologia da televisão digital. A escolha pelo modelo japonês, adaptado para o sistema nipo-brasileiro, aconteceu também considerando a possibilidade de multiplicação da programação

Rev. Cad.Comun, Santa Maria, v.20,n.1, art 1, p.1 de 24, jan/abr.2016 
como um elemento positivo a ser utilizado. A partir do ano 2000 , o assunto ganhou destaque durante o processo de escolha da tecnologia e a regulamentação da implantação do Sistema Brasileiro de TV Digital Terrestres (SBTVD-T).

Após a implantação da multiprogramação pela TV Cultura, foram criados pela União ações de expansão da multiprogramação por meio dos canais do Poder Executivo do Brasil NBR , a TV do Governo Federal), TV Escola e TV Saúde a partir do canal TV Brasil, a emissora pública da EBC Empresa Brasil de Comunicação. Há ainda a criação de novos canais Canal da Cultura que tem como objetivo alcançar, até 2019 em território nacional, todos os municípios com mais de 100 mil habitantes.

\section{CONSIDERAÇÕES FINAIS}

Especialmente em 2009, quando a TV Cultura colocou os dois canais de multiprogramação no ar enfrentando a Norma n01/2009 que havia acabado de ser implantada restringindo o uso da tecnologia, o assunto ganhou ampla repercussão e a TV Cultura, historicamente, passou a ser uma das referências em comunicação pública televisiva. A iniciativa de utilizar de maneira pioneira a multiprogramação passou a ser uma contribuição significativa para o aprimoramento do uso da tecnologia da televisão digital no Brasil. Tanto a norma quanto a ousadia da Fundação Padre Anchieta, paralelamente acontecendo com a realização do II Fórum Nacional de TVs Públicas, foram acontecimentos que contribuíram substancialmente para a retomada da discussão sobre, não apenas a multiprogramação e suas potencialidades, mas também a relevância da televisão pública e seu papel na sociedade na época.

Mesmo assim, a plena e efetiva utilização da multiprogramação tem sido um assunto pouco contemplado junto às decisões do Estado além do escopo da comunicação pública da União. Quando pensada para os canais comerciais, a multiprogramação passa a ficar dividida entre as emissoras, já que o aumento de investimentos em novas programações, a segmentação da audiência e o conteúdo a ser exibido nos canais são assuntos que não chegaram a um consenso. Por outro lado, para as emissoras públicas, a utilização da multiprogramação também apresenta desafios a serem superados em relação ao aumento de investimentos para a produção de programações diversificadas, mas apresenta-se extremamente atrativa

Rev. Cad.Comun, Santa Maria, v.20,n.1, art 1, p.1 de 24, jan/abr.2016 
quando pensada em seus objetivos de disseminação e acesso à informação, educação, cultura e entretenimento diversificado, alternativo e regionalizado.

Ao refletir sobre as propostas de uma televisão pública de qualidade e a atuação da TV Cultura, por meio da implantação da multiprogramação, é possível perceber que a contribuição da proposta inicial é de extrema relevância, especialmente por demonstrar possibilidades de desenvolvimento e aprimoramento do conteúdo produzido em novos canais, colaborando como referencial para os debates em busca de desenvolvimento, aperfeiçoamento e consolidação de modelo de televisão digital no Brasila, além da própria contemplação de princípios constitucionais.

No entanto, mesmo com debates e reivindicações sobre o tema, muito ainda há a ser feito. Faz-se necessário, em primeiro lugar, a criação e consolidação de uma regulamentação clara e efetiva para a contemplação dos princípios e objetivos da radiodifusão e da própria comunicação pública no Brasil, inclusive atendendo a demandas de investimento, qualificação, capacitação e abrangência. Posteriormente, necessita-se a viabilização da normatização do pleno uso das potencialidades da tecnologia digital buscando atender aos princípios da criação e implantação da tecnologia no Brasil que envolvem a finalidade de promover a inclusão social, a diversidade cultural do país e a língua pátria por meio de acesso à tecnologia, visando à democratização da informação, propiciando a criação de rede universal de educação a distância e contribuindo para a convergência tecnológica e empresarial dos serviços de comunicação não apenas públicos e estatais, mas também que envolvam os canais privados. 
CADERNOS DE COMUNICAÇÃO

UNIVERSIDADE FEDERAL DE SANTA MARIA

\section{REFERÊNCIAS}

BRASIL. Constituição da República Federativa do Brasil de 05/10/1988. Disponível em: http://www.planalto.gov.br. Acesso em 13/06/2010.

.Decreto n. 4.901 de 28 de novembro de 2003. Institui o Sistema Brasileiro de Televisão Digital SBTVD, e dá outras providências. Disponível em: http://www.planalto. gov.br/ccivil_03/decreto/2003/d4901.html. Acesso em 13/06/2010.

.Decreto n. 5.820 de 29 de junho de 2006. Dispõe sobre a implantação do SBTVD-T, estabelece diretrizes para a transição do sistema de transição digital do serviço de radiodifusão de sons e imagens e do serviço de retransmissão de televisão e dá outras providências. Disponível em: http://www.mc.gov.br/index.php/content/view/30843. html. Acesso em 13/06/2010.

.Decreto Lei $\mathrm{n}^{\circ} 236$ de 28 de fevereiro de 1967. Complementa e modifica a Lei número 4.117 de 27 de agosto de 1962. Disponível em:

http://www.planalto.gov.br/ccivil/Decreto-Lei/Del0236.htm. Acesso em 07/06/2011.

.NORMA No 01/2007, anexo a Portaria $\mathrm{n}^{\circ} 465$, de 22 de agosto de 2007. Estabelece os procedimentos operacionais necessários ao requerimento para a execução do Serviço Especial para Fins Científicos ou Experimentais, com o objetivo de realizar experimentos de transmissão de sinais de radiodifusão ou demonstrações de sistemas desenvolvidos para essa finalidade. Disponível em: http://www.anatel.gov.br/hotsites/ Direito_Telecomunicacoes/TextoIntegral/ANE/prt/minicom_20070822_465.pdf. Acesso em 05/03/2012.

. NORMA Nº1/2009. Norma Geral para Execução dos Serviços de Televisão Pública. Anexa a Portaria No 24, de 11 de fevereiro de 2009. Disponível em: http://www. astralbrasil.org/leis/portaria24fevereiro.pdf. Acesso em 18/06/2011.

.Portaria n ${ }^{\circ} 106$ de 2 de março de 2012. Estabelece normas para utilização de multiprogramação e para a operação compartilhada com entes públicos nos canais consignados a órgãos dos Poderes da União. Disponível em:

http://www.legisweb.com.br/legislacao/?legislacao=238185. Acesso em 29/05/2012.

.Portaria $\mathrm{n}^{\circ} 465$ de 22 de agosto de 2007. Aprovar a NORMA No 01/2007, que estabelece os procedimentos operacionais necessários ao requerimento para a execução do Serviço Especial para Fins Científicos ou Experimentais. Disponível em: ftp://ftp. saude.sp.gov.br/ftpsessp/bibliote/informe_eletronico/2007/iels.ago.07/iels165/U_PT-MC-GM-465_220807.pdf. Acesso em 05/03/2012.

. Portaria $\mathrm{n}^{\circ} 471$ de 22 de novembro de 2012, que altera o art. $3^{\circ}$ da Portaria $\mathrm{n}^{\circ}$ $\overline{106}$, de 2 de março de 2012, que estabelece normas para utilização de multiprogramação e para a operação compartilhada com entes públicos nos canais consignados a órgãos dos Poderes da União. Disponível em: <http://www.mc.gov.br/legislacao/por-ano/2012/portaria-n-471-de-22-de-novembro-de-2012>. Acesso em 14/04/2016.

BOLAÑO, C. R. S., BRITTOS, V. C. A televisão brasileira na era digital: exclusão, esfera pública e movimento estruturante. São Paulo: Paulus, 2007.

Rev. Cad.Comun, Santa Maria, v.20,n.1, art 1, p.1 de 24, jan/abr.2016 
DOU Diário Oficial da União Seção 1. Ministério das Comunicações. Despacho do Ministro n. 86, 8 de maio de 2009. ISSN 1677-7042, p. 65. Disponível em: http://www.in.gov. $\mathrm{br} /$ imprensa/visualiza/index.jsp?jornal=1\&pagina $=65 \&$ data $=08 / 05 / 2009$. Acesso em 28/07/2010.

FPA Fundação Padre Anchieta. Missão. Disponível em: http://www2.tvcultura.com.br/ fpa/. Acesso em 02/05/2010.

FERRAZ, C. Análise e perspectivas da interatividade digital, In: Televisão digital: desafios para a comunicação. Livro da Compós. Porto Alegre: Sulina, 2009.

INTERVOZES. Contribuição ao II Forum Nacional de TVs públicas, Intervozes - Coletivo Brasil de comunicação social: 2009.

LEAL FILHO, L. L.. Atrás das Câmeras: relação entre cultura, Estado e televisão. São Paulo: Summus, 1988.

LIMA, J. da C. Uma história da TV Cultura. São Paulo: Imprensa Oficial (IMESP), 2008.

PIERANTE, O. P., WIMMER, M. Revisando a televisão: definições, desafios e novos caminhos em tempo de digitalização, In: Televisão digital: desafios para a comunicação. Livro da Compós. Porto Alegre: Sulina, 2009.

RELATÓRIO DE GESTÃO 2009- 2010. - FPA, 2010.

Revista Pré-Univesp disponível no site: http://www.univesp.ensinosuperior.sp.gov.br/ preunivesp/. Acesso em: 15/06/2012.

ROMERO, Thiago. Aprendizado eletrônico. Agência Fapesp, 12/08/2008. Disponível em: http://agencia.fapesp.br/9262. Acesso em: 08/02/2012.

ROMERO, Thiago; SHIMIZU, Heitor. Univesp lança cursos. Agência Fapesp, 27/08/2009 Disponível em: http://agencia.fapesp.br/10978. Acesso em: 08/02/2012.

SITE MULTICULTURA. Sobre nós. Disponível em: <http://multicultura.cmais.com.br/ sobre-o-multicultura/quem-somos>. Acesso em: 14/04/2016.

SITE UNIVESP TV. Sobre a Univesp TV. Disponível em: <http://univesptv.cmais.com.br/ sobre-a-univesptv>. Acesso em: 14/04/2016.

TEIXERA, Mônica; NAOUM, Lisely. Univesp TV- Um canal para aprender sempre. Revista Pré-Univesp, junho de 2012. Disponível em: http://univesp.ensinosuperior.sp.gov.br/ preunivesp/3490/univesp-tv.html. Acesso em: 15/06/2012.

UNIVESP. Formação Superior ao alcance de todos. Disponível em: http://www.univesp. ensinosuperior.sp.gov.br/tv. Acesso em 03/07/2010.

UNIVESP TV. Univesp TV: o canal para quem quer saber mais e aprender sempre! Disponível em: http://www.univesp.tv.br/sobre-a-univesp-tv. Acesso em 05/11/2010.

Rev. Cad.Comun, Santa Maria, v.20,n.1, art 1, p.1 de 24, jan/abr.2016 


\section{Vivianne Lindsay Cardoso}

Doutoranda e Mestre em Comunicação pela FAAC/Unesp Universidade Estadual Paulista "Júlio de Mesquita Filho". Pesquisadora bolsista Capes. Orientador Prof. Dr. Juliano Maurício de Carvalho. Linha de pesquisa - Gestão e Política da Informação e da Comunicação Midiática. Especialista em Docência no Ensino Superior (Unifeob). Bacharel em Comunicação Social - Jornalismo (Puc-Campinas). Membro do Grupo de Pesquisa Lecotec (Laboratório de Estudos em Comunicação, Tecnologia e Educação Cidadã) vinculado a UFAAC/Unesp.e-mail:viviannelc@hotmail.com

\section{Juliano Maurício de Carvalho}

Coordenador do Programa de Pós-Graduação em Televisão Digital: Informação e Conhecimento (mestrado profissional), docente do Programa de Pós-Graduação em Comunicação Midiática (mestrado acadêmico) e do Curso de Jornalismo, líder do Lecotec (Laboratório de Estudos em Comunicação, Tecnologia e Educação Cidadã) da Universidade Estadual Paulista "Júlio de Mesquita Filho" (FAACl Unesp).e-mail: juliano@faac.unesp.br

*Este trabalho possui trechos do artigo apresentado no evento na modalidade Artigo Científico na IV Conferência Sul-Americana e IX Conferência Brasileira de Mídia Cidadã 2013. 
RECEBIDO EM: 01/05/2016

APROVADO PARA PUBLICAÇÃO: 18/05/2016

Rev. Cad.Comun, Santa Maria, v.20,n.1, art 1, p.1 de 24, jan/abr.2016 